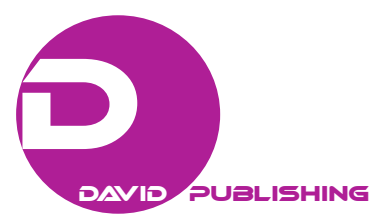

\title{
Research on Anonymous Expression of Chinese College Students in QQ Group from the Perspective of Media Literacy*
}

\author{
Huang Yi-ning, Hao Wen \\ Central China Normal University, Wuhan, China
}

\begin{abstract}
The anonymous chatting function of QQ group makes Chinese college students' self-awareness and herd mentality more obvious, showing the characteristics of exclusivity and collective emotional outburst of anonymous expression, and then reflects their lack of media literacy. This paper proposes three methods: enhance the cultivation of media literacy awareness, improve the theoretical cognition of media literacy, and form media literacy practical activities and platforms.
\end{abstract}

Keywords: network anonymity, QQ group, media literacy

\section{Research Background and Issues}

The development of Internet technology has promoted the innovation of instant communication tools, changing the audience's habits of media usage in a subtle way. As a result, audience became more active in creating, communicating, and exchanging information. At the forefront of Chinese new media environment, college students, the majority of young user group, are more likely to adapt new features appearing in media use. In 2014, Tencent updated the anonymous chatting function for QQ’s group chat. Chatting in QQ group anonymously is now a common phenomenon in Chinese campus.

New sociable characteristics were generated by the wide use of anonymous chatting function, which brought new challenges to the media literacy of college students. For college students who are both sender and audience, it is necessarily important to improve the ability of identifying media information, and to establish a proper media morality while using media.

The problems about how does anonymous expression of QQ group affect the media literacy of college students and how to improve the media literacy of college students in Chinese new media era will be discussed in detail in this paper.

\section{The Cause of the Lack of Media Literacy Among College Students}

Through participatory observation, the researchers find that in anonymous state, the expression of college students mainly presents two characteristics: exclusivity and collective emotional outburst. Anonymity

\footnotetext{
*Acknowledgements: This study was the phased research result of the Project "Research on Network Expression and Interactive Relationship of College Students in the New Era" supported by Youth Fund for Humanities and Social Sciences Research of the Ministry of Education (Project No. 20YJC710022). It was also the phased research result of Project of Research Association on College Youth Work of Hubei Province “Research on College Students’ Network Expression in the New Media Era” (Project No. GYHZD2019002).

Huang Yi-ning, G.MA., lecturer, School of Journalism and Communication, Central China Normal University.

Hao Wen, undergraduate, School of Journalism and Communication, Central China Normal University.
} 
amplifies self-awareness. Without the risk of exposing actual identity, subjects are more likely to verbally refute others, aggravating the collective emotional outburst driven by herd mentality. Effected by these two factors, the development of anonymous expression deviates from the requirements of media literacy.

\section{Self-Awareness and Exclusive Expression}

The border between "self" and "others" is blurred by the fake identity that anonymous function provides. Once "I" can become "anyone," the college students gain a sense of security that their actual identities will not be revealed, and thus they no longer concern about the impact on their real interpersonal relationships and individual image while expressing themselves. Therefore, when chatting anonymously in QQ groups, college students pay more attention to expressing their own opinions, especially the negative ones that they dare not express directly and clearly in the real-name status.

However, with both limited ability in critical thinking, and a strong self-awareness that anonymity provides, college students are more likely to ignore heterogeneous views from others. As a result, they are more likely to trust the source indiscriminately, and to attack others anonymously in order to defend their own opinions. Using a QQ group of a department from a central China's university as an example, group members were anonymously debating on whether a media report about the COVID-19 pandemic was objective, but it eventually turned into an "exclusive blame" between opposing sides, such as some students said, "You are ignorant when you hold such a silly view”.

\section{Herd Mentality and Collective Emotional Outburst}

Chatting anonymously in QQ group provides college students limitless courage to express personal opinions with limited latitude in communication space, especially when discussing about problems that personal interests are involved in. The collective emotions are more possible to be triggered and lead to a chain reaction under this circumstance. Individual impulses and dissatisfaction can cause a conflict, and for college students, "The stimulus gained from participating in an anonymous conflict outweighs the conflict itself” (You, 2018), which often results in "focus deviation," offering no benefit on solving the problem.

Many college students are ignorant about the aim of the debate when involved in the collective conflict, but following the crowd blindly because of being infected by the negative emotions from others. "Everything in society is either invented or imitated,” as Huang, Y. N. cited from French social psychologist G. Tarde in 2016. Group imitation leads to homogeneity of opinions and emotions in the QQ group, forcing the minority groups with different opinions to be suppressed. College students lose the ability to think independently and express themselves reasonably when facing the group effects caused by media, and thus become involved in triggered collective conflicts.

\section{Possible Approaches to Improve College Students' Media Literacy}

Zhang (2006) stated, "Media literacy refers to the ability of individuals to select, question, understand, evaluate, create, produce, and speculative abilities in responding while facing various information from various media." In a nutshell, it is the ability to serve society and individuals appropriately by judging and distinguishing media information properly. To improve the media literacy of college students in new media era, three following dimensions are considerable: awareness education, theoretical education, and practical education. 


\section{Enhancing the Cultivation of Media Literacy Awareness}

The level of media literacy cannot be assessed by test scores perspicuously. Therefore, many college students are not aware about their lack of media literacy in real life. Concerning about the anonymous expression in QQ groups, the "bystander" who can point out the problems with media literacy of college students should be tutors. Focusing on the tendency of communication atmosphere in QQ groups, and paying attention to the source cited by students while discussing public events, tutors should be aware of each individual's behavior, guiding them to maintain skeptical of the media as well as establishing appropriate values in their mind.

In order to arouse college students' awareness of media literacy, tutors could use "fear demand" to warn them, enumerate real cases, such as cyber violence and cyber fraud caused by lack of media literacy, and find relevant video recordings as intuitive and powerful evidence. Tutors could also use questionnaires to obtain the feelings of those who are not involved in anonymous discussions that related to exclusive expressions and collective emotional events, and then offer participators with feedback accordingly, acknowledging them that they once had a negative impact on the people around, so that these students will regulate their expressions in the future.

\section{Improving the Theoretical Cognition of Media Literacy}

In 2016, Kuang and Huang pointed out that in Western countries, such as Britain, France, and Australia, where mass communication is greatly developed, courses about media literacy education are offered by elementary schools, middle schools, and universities, while media literacy education in China is still in its infancy and only limited content about media literacy is included in elementary education's textbooks. In universities, media literacy courses are only offered to students who major in Journalism and Communication, meanwhile, the quantity and variety of courses are insufficient. Even if media literacy is required to take in few colleges, instead of improving students' media literacy awareness, carrying out ideological and political education is the main purpose. Thus, the political factor involved in public courses weakened the professionalism in the field of media literacy.

It is obvious that college students lack media literacy in anonymity environment. Therefore, colleges should set up a complete system about educating media literacy theory as well as updating course framework with latest researches. Incorporating media literacy education into the compulsory courses, offering variety of elective and lectures, and bringing the academic explanation of media literacy from different dimensions, so as to improve students' theoretical cognition are all considerable approaches universities can take.

\section{Forming Media Literacy Practical Activities and Platforms}

Kuang and Huang (2016) also pointed out that, compared with ordinary courses, media literacy education requires vast practices due to the widespread of media. Colleges could combine theory with practice by organizing various campus activities, like quiz tournaments, speech competitions, debates, etc., which might increase students' interest in exploring the field of media literacy, stimulate their enthusiasm for media use, and improve their ability of critical thinking.

In addition, with its extensive influence and practicality among students, campus media has become a platform to propel media literacy education in colleges. Colleges should encourage students to participate in campus media with the guidance of professional teachers, experiencing the media operation process, in order to grasp variety of media technologies, thus gaining initiative in the game between audience and media. 
Competent colleges could further set up some off-campus practical projects, cooperating with social media to cultivate all-media technical talents. By participating in media departments, such as radio station and television station, students are able to obtain the chance of producing various media products as they are immersed in a professional atmosphere. Thus, students' ability of using media could be improved, which would be used in serving society and individuals, furthermore, improving their awareness of social responsibility and allowing the unification of media knowledge, media capabilities, as well as media morality.

\section{Conclusion}

In the new media era, that college students express themselves anonymously online is no longer a surprise. The QQ group does provide college students a free platform of exchanging information, while exposing the lack of media literacy among them. The actual crisis behind anonymity was revealed in this paper, reminding college students do not fall into the trap of media layout. It also rang the bell for college student-work managers and relating functional departments to beware of the new media ecology and attach importance to media literacy education, thus guiding students to use media reasonably and appropriately.

\section{References}

Huang, Y. N., \& Yang, X. X. (2016). Research on Internet public opinion events of college students from the perspective of collaborative governance-Taking anonymous public opinion events of QQ group as examples. Decision and Information, (5), 119-127.

Kuang, L. B., \& Huang, Y. J. (2016). Research on the path of college students' media literacy improvement in the perspective of new media. Inheritance, (11), 79-81.

You, X. Y. (2018). Research on anonymization in network cluster behavior. Journal of Shanxi Institute of Economic Management, 26(3), 85-87.

Zhang, K. (2006). Introduction to media literacy. Beijing: Communication University of China Press. 